\title{
Evolution of Anisotropy in Granular Materials: Effect of Particle Rolling and Particle Crushing
}

\author{
L. L. Zhou, X. H. Chu, ${ }^{1}$ and Y. J. Xu \\ Department of Engineering Mechanics, Wuhan University, Wuhan, China \\ ${ }^{1}$ chuxh@whu.edu.cn
}

УДК 539.4

\section{Влияние скатывания и дробления частиц на эволюцию анизотропии гранулированных материалов}

\author{
Л. Л. Жоу, к. Х. Чуํㅜ, Я. Ж. Ксу \\ Факультет машиностроения, Уханьский университет, Ухань, Китай
}

Представлено численное исследование с помощью метода дискретных элементов влияния скатывания и дробления частии на эволюиию анизотропий скатывания частии (микроструктура) и силовой цепочки. Для описания анизотропии микроструктуры используется структурный классический тензор, а два аналогичных тензора ориентачии, характеризуюшихся направлением контактных усилий, - для определения анизотропии силовой ијепочки. Результаты численного исследования показали, что эволюиия анизотропий имеет тот же характер, что и зависимость деформации от напряжения, однако анизотропия силовой цепочки является более интенсивной по сравнению с анизотропией микроструктуры. Более того, скатывание частии по-разному влияет на анизотропию до и после достижения максимального значения напряжения, тогда как дробление частии уменьшает анизотропию гранулированных материалов.

Ключевые слова: гранулированные материалы, анизотропия, метод дискретных элементов, скатывание частиц, дробление частиц.

Introduction. Granular materials consist of particles in contact at the microlevel and transfer the loads through the contact points. The micromechanical characteristics of the particle assembly, such as the orientation distributions of contacts, contact forces, etc., are of great importance for the macro- mechanical behaviors of granular materials. The average orientation of contacts can be described by an anisotropic fabric tensor [1], which has been widely used to characterize the anisotropic behaviors of granular materials based on the continuum approach $[2,3]$. However, the evolution of fabric tensor cannot be directly obtained based on the continuum approach.

The discrete element method has been widely used to investigate the evolution of fabric tensor in granular materials due to its advantage in capturing the detailed information on the microlevel. Kruyt [1] investigated the physical mechanisms of fabric evolution by decomposing the change of fabric tensor into contributions due to three mechanisms: contact creation, contact disruption and contact reorientation. Guo and Zhao [4] investigated the characteristics of shear-induced anisotropy in granular materials based on the threedimensional discrete element method (DEM) simulations. Despite the importance of particle rolling on the micro-macro behavior of granular materials $[5,6]$, there are few investigations on the effect of particle rolling on the evolution of anisotropy in granular 
materials. One aim of this study is to investigate the evolution of anisotropy based on the discrete element method incorporating rolling resistance. The classical fabric tensor is adopted to describe the anisotropy of microstructure, and another two orientation tensors are defined to represent the orientation distribution of contact forces in granular materials. The reasons why these two orientation tensors need to be defined are as follows. The fabric tensor cannot quantify the orientation distribution of contact forces when tangential forces exist at contact points. Moreover, the anisotropy of contact forces is more effective to reflect the anisotropy of the macroscopic behavior of granular materials since the contact forces are directly related to the external loads.

Another aim of this study is to investigate the evolution of anisotropy in crushable granular materials. Particle crushing and its influence has been focused previously [7-11]. In general, there are two approaches to simulate particle crushing in the discrete element method. The first one is that the crushable particle is considered as an agglomerate of bonded smaller particles that can disaggregate when the interaction force between bonded particles is above the bond strength $[7,8]$. The second one assumes that particles will crush when the failure criterion is satisfied and will be replaced with a group of smaller sub-particles according to the particle crushing model [9-11]. The failure criterion and crushing model describing the distribution of sub-particles should be predetermined. In this paper, the second approach is utilized to investigate the effect of particle crushing on the fabric tensor and the orientation distribution of contact forces.

Orientation Tensors. To quantify the overall orientation of the particle contact normal in granular materials, the second order fabric tensor can be defined as follows [1]:

$$
\Psi_{i j}=\frac{1}{N_{c}} \sum_{k=1}^{N_{c}} n_{i}^{k} n_{j}^{k},
$$

where $N_{c}$ is the total number of contacts and $n_{i}^{k}$ is the component in direction $i$ of the unit contact normal vector. In two-dimensional cases, $i$ and $j$ take values 1,2 and the fabric tensor $\Psi_{i j}$ has two principal values $\Psi_{1}$ and $\Psi_{2}$. The sum of the two principal values is the unity $\left(\Psi_{1}+\Psi_{2}=1\right)$ which implies that there is only one independent variable. The anisotropy of the material is then taken as the difference between the major and the minor principal components of fabric tensor: $A=\Psi_{1}-\Psi_{2}$. For an isotropic material, there will be $\Psi_{1}=\Psi_{2}=0.5$.

To characterize the orientation of contact forces, another orientation tensor is defined as follows:

$$
\begin{gathered}
\Phi_{i j}=\frac{1}{N} \sum_{k=1}^{N} m_{i}^{k} m_{j}^{k}, \\
\mathbf{m}=\frac{\mathbf{F}}{|\mathbf{F}|}, \quad \mathbf{F}=f_{n} \mathbf{n}+f_{t} \mathbf{t},
\end{gathered}
$$

where $\mathbf{m}$ is the unit direction vector of contact forces. Similar to those in Eq. (1), $m_{i}^{k}$ is the component in direction $i$ of the unit contact force vector, $\mathbf{F}$ is the contact force vector, $f_{n}$ and $f_{t}$ are the normal and tangential contact forces, respectively, while $\mathbf{n}$ and $\mathbf{t}$ are the contact normal and tangential direction vectors, respectively.

In general, the strong contact forces greater than the average force play an important role in mechanical behavior of granular materials. Therefore, the following tensor to characterize the orientation of strong contact forces is defined: 


$$
\bar{\Phi}_{i j}=\frac{1}{\bar{N}} \sum_{k=1}^{\bar{N}} m_{i}^{k} m_{j}^{k},
$$

where $\bar{N}$ is the total number of contact points bearing strong contact forces.

Implementation of Particle Rolling and Crushing. Particle Rolling. Recognizing the significant role of particle rolling in the mechanical behaviors of granular materials, many researchers have proposed various contact models incorporating particle rolling [7-11]. In this study, the normal and tangential contact forces are calculated by the linear model in the DEM code PFC2d, in which the increments of normal and tangential contact forces are proportional to the increments of normal and tangential displacements, respectively, while the tangential contact force needs to satisfy Coulomb criterion. The rolling moment is computed by a model which can be easily implemented by PFC2d code:

$$
M_{r}=-k_{r} \theta_{r}
$$

where $k_{r}$ is the constant rolling stiffness and $\theta_{r}$ is the relative rotation between two particles in contact [6].

Particle Crushing. Particle crushing inevitably disturbs the stability of force chains at the microscopic level, which results in the change of the macromechanical behavior. Similarly to particle motions, such as sliding, rotating, and rolling at the microscopic level, particle crushing also plays an important role in the macroscopic deformation of a crushable particle assembly. In this study, particle crushing is implemented using PFC2d. The approach used in the simulations is that a crushable particle will crush if the failure criterion is satisfied, and the particle is replaced with sub-particles according to the particle crushing model. The failure criterion adopted to determine particle crushing is based on the Weibull statistics of fracture, which was also used by Chu and Li [11]. The crushing model referred to as model A, which was used in our simulations, has been proposed by Lobo-Guerrero and Vallejo [10]: a particle is replaced by a set of eight sub-particles of three different sizes as shown in Fig. 1a.

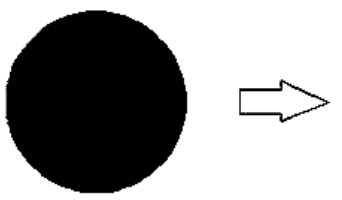

a

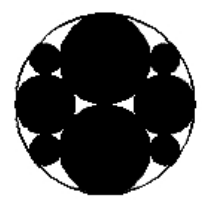

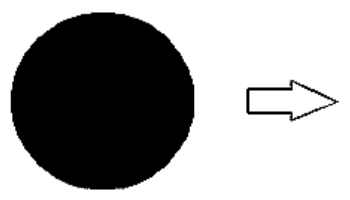

$\mathrm{b}$

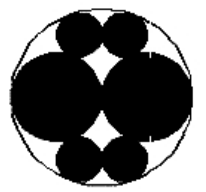

Fig. 1. Crushing models used in the numerical simulations: (a) model A; (b) model B.

It is observed that the distribution of contact orientation within the sub-particles in model A is anisotropic, and the probability of contacts oriented along the vertical direction is higher than in the horizontal one. This anisotropy within the sub-particles of crushing model may affect the overall anisotropy of the assembly. In order to verify the effect of particle crushing model, another crushing model, model $\mathrm{B}$, is also applied in the simulations. According to model $\mathrm{B}$, the crushed particle will break into a set of six sub-particles of two different sizes as shown in Fig. 1b. The contacts within model B are mostly oriented along the horizontal direction.

Numerical Test. Two-dimensional numerical biaxial compression tests are carried out using the discrete element code PFC2d. The biaxial box has originally a width of $90 \mathrm{~mm}$ and a height of $180 \mathrm{~mm}$, which is contained within four frictionless walls. A specimen generation method called "radius expansion method" is used to generate the granular 
assembly in the biaxial box. This assembly consists of 5792 particles with a radius distribution in the range of $0.75-1.0 \mathrm{~mm}$. After the desired number of particles is generated, the assembly is isotropically consolidated with a hydrostatic pressure of $1 \mathrm{MPa}$. Then the shear loading of the assembly is performed by increasing the vertical strain. The top and bottom walls move in the vertical direction toward each other with a constant velocity, while the velocity of the lateral walls is controlled by a servo-control algorithm to maintain a constant confining stress.

The parameters used in the study are summarized in Table 1 . The normal stiffness of the top and bottom walls is the same as that of the particle, while the normal stiffness of the left and right walls treated as semi-rigid walls is $1 / 10$ th of the respective value of the particle. To investigate the influence of rolling friction, the biaxial tests are run with the rolling friction coefficient $\mu_{\theta}$ varying from 0 to 0.3 , the values of other model parameters are kept the same as is shown in Table 1 . For $\mu_{\theta}=0$, there is no rolling resistance at the contact points. The value of $\mu_{\theta}=0.3$ indicates a high rolling friction.

$\mathrm{T}$ a b 1 e 1

Model Parameters Used in the DEM Simulations

\begin{tabular}{|l|c||}
\hline \multicolumn{1}{|c|}{ Model parameter } & Value \\
\hline Biaxial box dimensions $(\mathrm{mm})$ : height/width & $180 / 90$ \\
\hline Number of particles & 5792 \\
\hline Particle size $(\mathrm{mm})$ & $0.75-1.0$ \\
\hline Particle density $\left(\mathrm{kg} / \mathrm{m}^{3}\right)$ & 1000 \\
\hline Initial void ratio & 0.14 \\
\hline Particle normal stiffness $(\mathrm{N} / \mathrm{m})$ & $5.0 \cdot 10^{8}$ \\
\hline Particle tangential stiffness $(\mathrm{N} / \mathrm{m})$ & $2.5 \cdot 10^{8}$ \\
\hline Inter-particle sliding friction coefficient & 0.5 \\
\hline Particle rolling stiffness $(\mathrm{N} \cdot \mathrm{m})$ & 5000 \\
\hline Inter-particle rolling friction coefficient & $0,0.1,0.2,0.3$ \\
\hline Top and bottom walls' normal stiffness $(\mathrm{N} / \mathrm{m})$ & $5.0 \cdot 10^{8}$ \\
\hline Left and right walls' normal stiffness $(\mathrm{N} / \mathrm{m})$ & $5.0 \cdot 10^{7}$ \\
\hline Confining stress $(\mathrm{MPa})$ & 1.0 \\
\hline
\end{tabular}

In this study, a contact model incorporating particle rolling is introduced in PFC2d. This approach has been used by many researchers, referring to work of Mohamed at al. [6]. The stress of each particle will be computed to determine particle crushing according to the failure criterion at the beginning of each step. The particle that satisfies the failure criterion is replaced by a group of small sub-particles according to the crushing model. The properties of the sub-particles are same as that of the crushed particle. However, the density needs to be recalculated to ensure mass conservation since the total solid volume of the sub-particles in Fig. 1 is less than that of the crushed particle.

Effect of Rolling Friction. To investigate the effect of rolling friction on the stress-strain and the evolution of anisotropy of granular materials, the rolling friction coefficient attains values $0,0.1,0.2$, and 0.3 , respectively. Other model parameters confining stress and initial void ratio are the same for all $\mu_{\theta}$ values. 


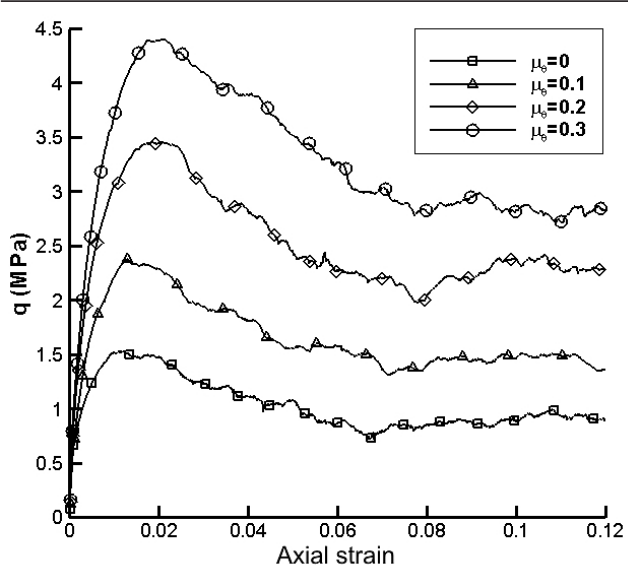

$\mathrm{a}$

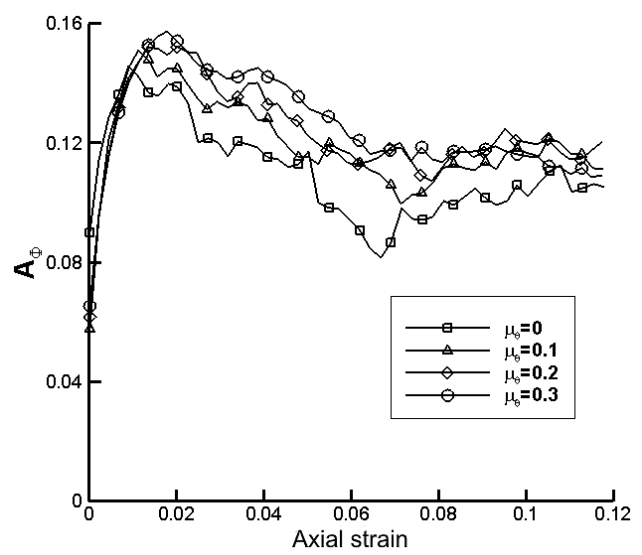

$\mathrm{c}$

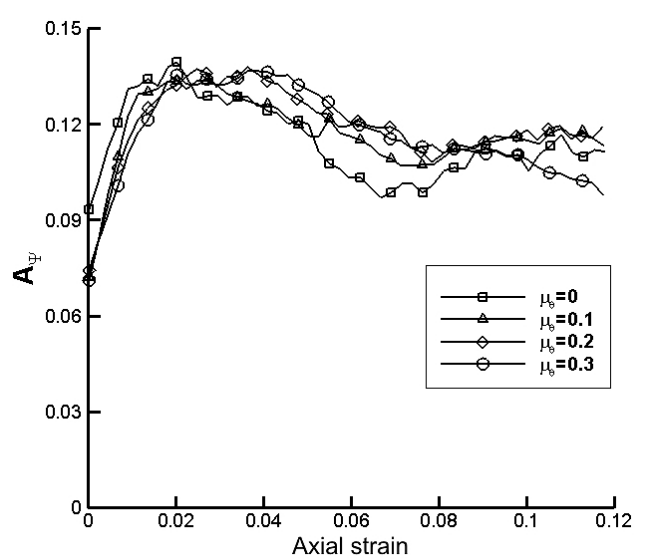

$\mathrm{b}$

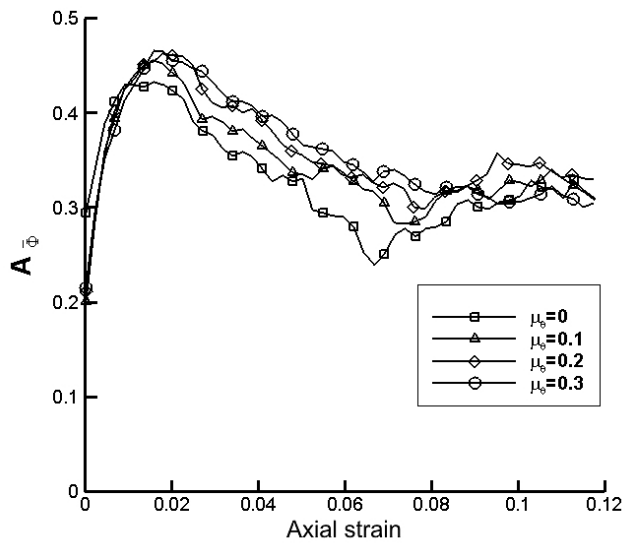

d

Fig. 2. Effect of the rolling friction on the stress-strain behavior and the evolution of anisotropies of the assemblies: (a) deviator stress-strain curves; (b) evolution of anisotropy of fabric tensor; (c) evolution of anisotropy of force chains; (d) the evolution of anisotropy of strong force chains.

The deviator stress-strain curves of assemblies are shown in Fig. 2a. It can be seen that the deviator stress $q$ (i.e., $\sigma_{1}-\sigma_{2}$ ) increases quickly to its peak at about axial strain $2 \%$ for all rolling frictional coefficients, and then decreases to some extent and remains constant during further loading. This indicates that the critical state stage appears. It is also easy to observe that the peak deviator stress increases significantly with the increasing rolling friction coefficient $\mu_{\theta}$. The increase in the peak deviator stress with the increasing $\mu_{\theta}$ indicates that the rolling resistance enhances the overall friction resistance of granular materials. In addition, the post-peak strain softening is more obvious for high $\mu_{\theta}$ values.

The fabric anisotropy can be measured by the difference between the principal values of fabric tensor $[2,5]$. The three orientation tensors, including fabric tensor $\Psi$, orientation tensor $\Phi$ of contact forces, and orientation tensor $\bar{\Phi}$ of strong contact forces, are investigated for various rolling friction coefficients. The differences between the principal values of these three tensors are denoted as $A_{\Psi}, A_{\Phi}$, and $A_{\bar{\Phi}}$, respectively. Figure $2 \mathrm{~b}-\mathrm{d}$ shows the evolutions of anisotropies of these three tensors with axial strain for different rolling friction coefficients. It is observed that the values of $A_{\Psi}, A_{\Phi}$, and $A_{\bar{\Phi}}$ for all $\mu_{\theta}$ values increase with axial strain increasing, atttain their peak values at strain level of about 


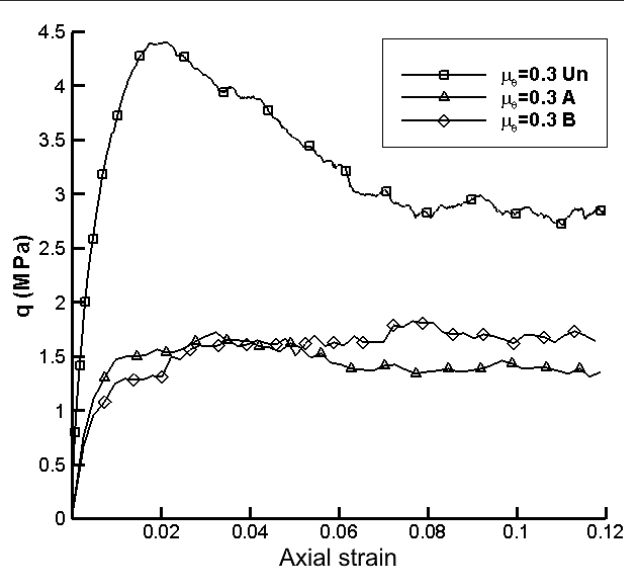

$\mathrm{a}$

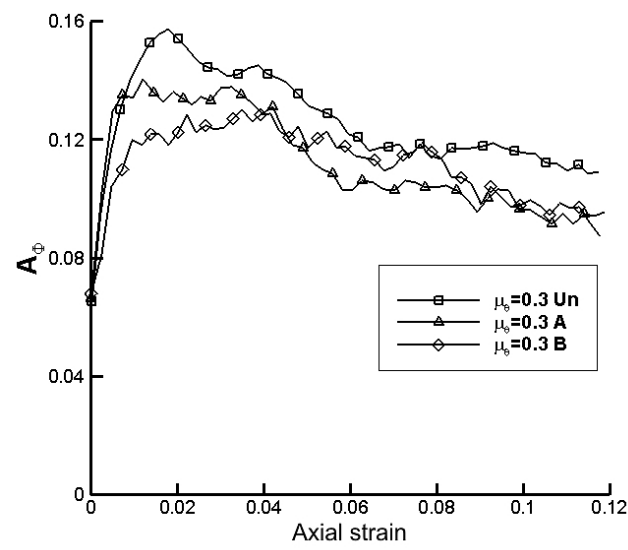

$\mathrm{c}$

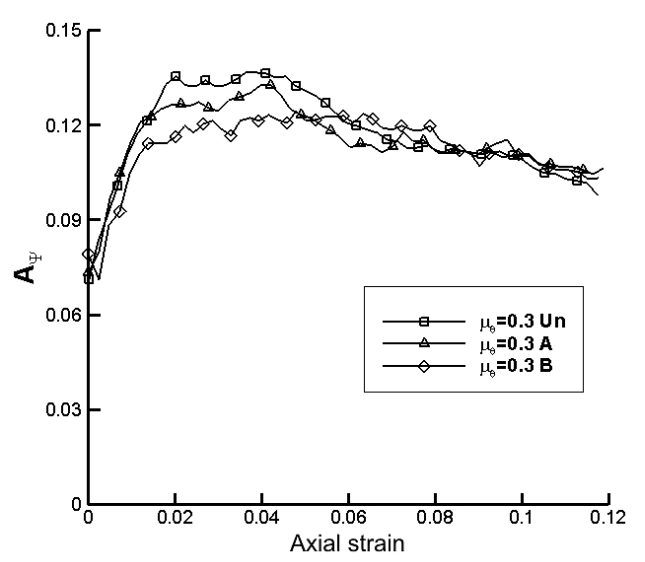

$\mathrm{b}$

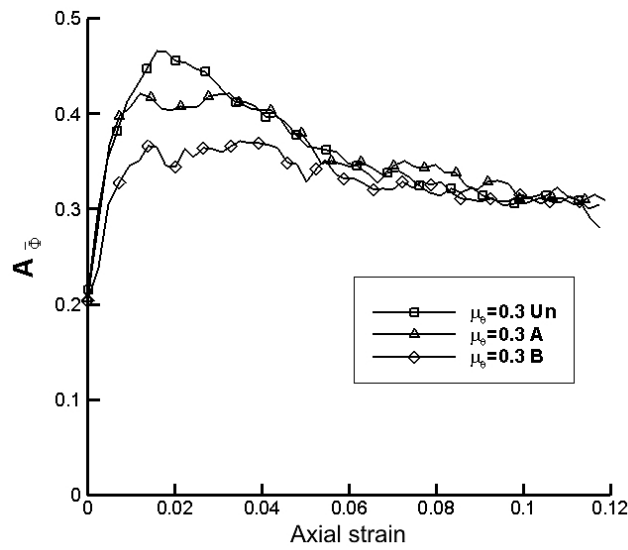

d

Fig. 3. Effect of particle crushing on the stress-strain behavior and the evolution of anisotropies of the assemblies: (a) deviator stress-strain curves; (b) evolution of anisotropy of fabric tensor; (c) evolution of anisotropy of force chains; (d) evolution of anisotropy of strong force chains.

$2 \%$, and then drop down. Comparison of Fig. $2 \mathrm{~b}, 2 \mathrm{c}$, and $2 \mathrm{~d}$ shows that the evolution trends of the anisotropies of these three tensors are similar. The only difference between them is the intensity of anisotropy. The anisotropy of strong force chains is the most intense, and the anisotropy of fabric tensor is the weakest. In addition, it is seen from Fig. $2 \mathrm{~b}$ that the values of $A_{\Psi}$ for low $\mu_{\theta}$ values are higher than those for high $\mu_{\theta}$ values before axial strain reaches about $2 \%$, but the former has a more significant reduction than the latter with further loading. At large strains exceeding $2 \%$ the values of $A_{\Psi}$ for low $\mu_{\theta}$ values are lower than those for high $\mu_{\theta}$ values. In Fig. $2 \mathrm{c}$ and $2 \mathrm{~d}$, the rolling friction coefficient $\mu_{\theta}$ has a strongly manifested effect on the values of $A_{\Phi}$ and $A_{\bar{\Phi}}$ before the peak values at the axial strain of about $2 \%$, except for $\mu_{\theta}=0$. However, the peak values of anisotropies of forces chains and strong forces chains increase with the increasing $\mu_{\theta}$ value, and the values of anisotropies of these two tensors for high $\mu_{\theta}$ values are still higher than those for low $\mu_{\theta}$ values with further loading.

Effect of Particle Crushing. In order to investigate the influence of particle crushing on the mechanical behaviors of granular materials, a series of numerical biaxial tests with particle crushing are conducted providing rolling frictional coefficient $\mu_{\theta}=0.3$. All values 
of other model parameters, confining stress and the initial void ratio are kept the same as in Table 1. The symbol "Un" in the legend in Fig. 3 represents the uncrushable case. The symbol " $A$ " and " $B$ " mean the crushable case using the crushing model $\mathrm{A}$ and model $\mathrm{B}$, respectively.

The deviator stress-strain curves of assemblies are shown in Fig. 3a. The peak deviator stresses of two crushable cases decrease significantly, as compared to the uncrushable case. The post-peak strain softening also exhibits a significant reduction in the crushable cases. However, the difference between the deviator stress-strains curves of two crushable cases is small. This means that these two crushing models have a minor effect on the stress-strain behavior of the crushable assembly.

The evolution curves of anisotropies of fabric and contact force chains with axial strain under the biaxial compression with particle crushing are shown in Fig. 3b-d. It can be observed that the tendencies of evolutions of the anisotropies of these three tensors for crushable granular assemblies are similar to the curves without particle crushing, and the peaks of curves also occur at the same axial strains. However, particle crushing results in lower peak values of the anisotropies. Microscopically, the contact force chains and the contact normal vectors align more in the direction of major principal stress (i.e., the vertical direction) when the peaks at the axial strain $2 \%$, which results in the intense anisotropies at the peak stress state. For crushable cases, the large particle-to-particle contact forces cause crushing of many particles. As a result, the contact force chains may collapse, therefore the contact force chains and the contact normal vectors deviate from the major principal stress direction. Particle crushing disturbs the stability of force chains at the microscopic level and weakens the anisotropies of assemblies. The effects of particle crushing on the anisotropies are in agreement with the results obtained by Wang and Yan [8]. In their simulation, the crushable particles were simulated by the agglomerates of bonded smaller particles. In addition, it can be can also be noted that the effect of using crushing model B has the same tendency as that of using crushing model A, but with larger reductions of the values of anisotropies. This indicates that the two crushing models in the study affect only the degree of the reductions of the anisotropies.

Conclusions. The main objectives of this study are to analyze the effects of particle rolling and particle crushing on the anisotropy in granular materials. The microstructure anisotropy is described by the fabric tensor defined by contact normal directions. Another two tensors, defined by the orientation of contact forces, are used to characterize the anisotropy of force chains in granular materials. The numerical results show that the evolutions of anisotropies of the three tensors follow the same tendency as the deviator stress-strain curve. As compared to the microstructure anisotropy described by the fabric tensor, the anisotropy of the force chains is more intense.

Numerical examples focus on the effects of particle rolling and particle crushing on the evolutions of anisotropies of the three tensors. The simulations are based on the user-defined model for particle rolling and apply the failure criterion based on the Weibull statistical theory and simplified crushing models, in order to achieve particle crushing in PFC2D code. According to the results of performed simulations, before the peak stress state, the increasing rolling friction reduces the microstructure anisotropy and has no obvious effect on the anisotropy of force chains. After the peak stress state, the anisotropies of the three tensors increase with the increasing rolling friction. Particle crushing has a minor effect on the tendencies of evolutions of the anisotropies, but significantly weakens the anisotropies of the three tensors. The two crushing models in the study only affect the degree of the reductions of particle crushing of the anisotropies.

Acknowledgments. The authors are pleased to acknowledge the support of this work by the National Natural Science Foundation of China through Contract/Grant Nos. 10802060 and 11172216 and the Natural Key Basic Research and Development Program of China (973 Program) through Contract/Grant No. 2010CB731502. 


\section{Резюм е}

Представлено чисельне дослідження за допомогою методу дискретних елементів впливу скочування і дроблення частинок на еволюцію анізотропій скочування частинок (мікроструктура) і силового ланцюжка. Для опису анізотропії мікроструктури використовується структурний класичний тензор, а два аналогічних тензора орієнтації, що характеризуються напрямком контактних зусиль, - для визначення анізотропії силового ланцюжка. Результати чисельного дослідження показали, що еволюція анізотропій має той же характер, що і залежність деформації від напруження, однак анізотропія силового ланцюжка є більш інтенсивною порівняно з анізотропією мікроструктури. Більш того, скочування частинок по-різному впливає на анізотропію до і після досягнення максимального значення напруження, в той час як дроблення частинок зменшує анізотропію гранульованих матеріалів.

1. N. P. Kruyt, "Micromechanical study of fabric evolution in quasi-static deformation of granular materials," Mech. Mater., 44, 120-129 (2012).

2. Y. F. Dafalias, A. G. Papadimitriou, and X. S. Li, "Sand plasticity model accounting for inherent fabric anisotrophy," J. Eng. Mech., 130, No. 11, 1319-1333 (2004).

3. R. G. Wan and P. J. Guo, "Stress dilatancy and fabric dependencies on sand behavior," J. Eng. Mech., 130, No. 6, 35-45 (2004).

4. N. Guo and J. D. Zhao, "The signature of shear-induced anisotropy in granular media," Comput. Geotech., 47, 1-15 (2013).

5. J. Ai, J. F. Chen, J. M. Rotter, and J. Y. Ooi, "Assessment of rolling resistance model in discrete element simulation," Powder Technol., 206, 269-282 (2011).

6. A. Mohamed and M. Gutierrez, "Comprehensive study of the effects of rolling resistance on the stress-strain and strain localization behavior of granular materials," Granul. Matter, 12, 527-541 (2010).

7. W. L. Lim and G. R. McDowell, "Discrete element modeling of railway ballast," Granul. Matter, 7, 19-29 (2005).

8. J. F. Wang and H. B. Yan, "On the role of particle breakage in the shear failure behavior of granular soils by DEM," Int. J. Numer. Anal. Meth. Geomech., 37, 832-854 (2013).

9. O. Tsoungui, D. Vallet, and J. C. Charmet, "Numerical model of crushing of grains inside two-dimensional granular materials," Powder Technol., 105, 190-198 (1999).

10. S. Lobo-Guerrero and L. E. Vallejo, "Discrete element method evaluation of granular crushing under direct shear test conditions," J. Geotech. Geoenviron. Eng., 131, No. 10, 1295-1300 (2005).

11. X. H. Chu and X. K. Li, "Hierarchical multiscale discrete particle model and crushing simulation," J. Dalian Univ. Technol., 46, 319-326 (2006).

Received 22. 11. 2013 